\title{
A AGOGÉ ESPARTANA
}

\author{
Luciene de Lima Oliveira* \\ (Universidade do Estado do Rio de Janeiro)
}

\begin{abstract}
RESUMO: Em Esparta, a coragem fazia parte da formação do caráter de um homem. O desenvolvimento da coragem era uma obsessão espartana, os guerreiros não deviam ter medo de nada, sendo resistentes aos ferimentos, odiando qualquer demonstração de covardia e, extremamente, dedicados à pólis. Cada espartano tinha de ser um soldado perfeito e sua maior glória era morrer em batalha; retornar derrotado, jamais. Desse modo, toda a sociedade e educação espartana estavam voltadas para a guerra. Uma das frases atribuídas às mães espartanas era: "espero que meu filho volte com o seu escudo, ou deitado sobre ele". Assim é que este artigo tem por escopo discorrer a respeito da agogé espartana, que era um tipo de educação peculiar com fins extremamente belicosos.
\end{abstract}

Palavras-Chave: Esparta; agogé; guerra; Licurgo.

\section{THE SPARTAN AGOGÉ}

ABSTRACT: In Sparta, courage was part of the formation of a man's character. The development of courage was a Spartan obsession. Spartans should not be afraid of anything, showing themselves resistant to wounds. They hated any type of cowardice and were extremely dedicated to the pólis. Each Spartan male had to be a perfect soldier and the ultimate glory was to die in battle, to never come back defeated. Given this, Spartan society and education was focused on war. One famous sentence related to Spartan mothers was: "I hope my son comes back with his shield - or on it". Thus, this article has as its scope the discussion of the practices of Spartan agogé, their very peculiar education with extremely bellicose objectives.

KEYWORDS: Sparta; agogé; war; Lycurgus.

Esparta tem de pleno direito um lugar na história da educação. A criação mais característica de Esparta é o seu estado e o Estado representa aqui, pela primeira vez, uma força educadora no mais vasto sentido da palavra. (Werner Jaeger)

\footnotetext{
*E-mail: oliveira-11@uol.com.br
} 
Esparta, também intitulada Lacedemônia, era a principal cidade de uma região denominada Lacônia, na região do Peloponeso. A cidade localizava-se às margens do rio Eurotas, cercada de montanhas a nordeste.

Os primeiros invasores da região foram os aqueus; esses expulsaram os povos préhelênicos, que ali habitavam, e fundaram a cidade de Lacedemônia.

A migração dórica é o último dos movimentos de povos, possivelmente originários da Europa Central, que a partir da Península Balcânica, entraram na Grécia e se misturaram com os povos de outras raças mediterrâneas ali fixadas primitivamente, constituindo assim o povo helênico.

Os dórios, ao se apoderarem da maior parte do Peloponeso, invadiram Creta e foram os responsáveis pela colonização de algumas ilhas Cicládicas e Espóradas. Os espartanos são considerados descendentes dos dórios ${ }^{1}$, esses tinham, por característica peculiar, a belicosidade.

A cidade de Esparta era conhecida por usufruir de uma eunomía, "uma boa legislação". De acordo com a tradição, Licurgo, após consultar o oráculo de Delfos ${ }^{2}$, teria dado à Esparta leis para a vida social e econômica, citem-se, por exemplo: a proibição do comércio e a utilização de metais preciosos, que foram substituídos por moedas de ferro, instituiu uma educação rigorosa, as refeições coletivas, regulamentação do casamento, a maneira de viver etc.

Os espartanos eram considerados xenofóbicos. Plutarco escreve que eles não tinham permissão para sair da cidade, pois poderiam trazer costumes estranhos e desordenados para dentro da cidade. Os estrangeiros, que residiam em Esparta, foram expulsos, com exceção daqueles que faziam algo de útil para a cidade. Além do mais, não comercializavam com o estrangeiro, nenhum navio de fora entrava no porto para ali comercializar (PLUTARCO. Licurgo XIV, LVII. In: Vidas Paralelas).

Ora, foi o historiador Heródoto o primeiro a retratar Licurgo como o idealizador da eunomía, se dedicando "às coisas relacionadas com a guerra" (HERODOTO. História I). Na Antiguidade, já havia dúvidas sobre a sua época e, até mesmo, sua existência.

Os espartanos - ao contrário de outros grupos - não desenvolveram relações culturais e comerciais externas; sua crescente população só encontrou um meio de expandir-se: pelas armas.

Xenofonte, inclusive, indaga como Esparta, uma das cidades menos povoadas, tornou-se a mais poderosa e famosa dentre toda a Hélade (JENOFONTE. La Republica de los Lacedemonios I. 1-2).

O vocábulo que os espartanos empregavam, para designar "educação", era agogé, que provém do verbo ágo, "transporto, conduzo". Os filósofos Platão (PLATÃO. Leis

\footnotetext{
${ }^{1} \mathrm{O}$ helenista Jaeger faz a seguinte ponderação a respeito dos dórios: “a raça dórica ofereceu a Píndaro o seu ideal de homem loiro, de alta estirpe, tal como era representado não só o Menelau de Homero, como também o herói Aquiles e, de um modo geral, os "helenos de loira cabeleira" da antiguidade heroica (JAEGER, 2001, p. 111).

${ }^{2}$ Esparta, pelo viés político, constituía uma diarquia hereditária real. Acredita-se que Licurgo fora descendente de uma das famílias reais de Esparta, a euripôntida. O legislador tinha um irmão rei, mas após a morte daquele, Licurgo subiria ao trono, porém o seu irmão havia deixado um descendente ainda no ventre de sua esposa, Leobotas. O legislador foi então tutor de seu sobrinho. Preocupado com a situação de Esparta, já que o sobrinho era uma criança, Licurgo se dirigiu a Delfos para receber conselhos, diga-se leis escritas, a rhétra, em relação a Esparta (HERÓDOTO. História I, LXV). Sabe-se muita coisa de Licurgo por meio de Plutarco em Vida de Licurgo.
} 
659d) e Aristóteles (ARISTÓTELES. Política 1.32.1) também se referem a agogé como "educação".

Entrementes, Marrou emprega o termo "adestramento" para traduzir agogé e chama a atenção para o fato de ser "uma condição necessária, senão suficiente para o exercício dos direitos cívicos" (MARROU, 1966, p. 41). O helenista considera que a educação em Esparta possui não só um lugar especial na história da educação como também na cultura grega (Op. cit., p. 33).

Todos os cidadãos espartanos tinham uma participação ativa na educação militar, constituindo uma casta aristocrática a priori, lembrando a educação da antiga nobreza grega. Não obstante, foi, mais tarde, estendida àqueles que não faziam parte da nobreza.

Jaeger expõe que, mesmo que Licurgo tenha realmente existido e criado a rhétra, "leis escritas", que o poeta Tirteu (4W 1-10) bem a conhecia já no século VII a.C., não adiantaria muito saber a respeito da origem da educação espartana, conforme Xenofonte a descreve (JAEGER, 2001, p. 114).

O pesquisador considera também a agogé como "o adestramento espartano", que nada mais era do que o ideal do movimento educativo do século IV a.C. (Op. cit., p. 115). O helenista destaca que a crença de que a educação espartana era uma preparação militar tinha sua origem na Política de Aristóteles. Platão, igualmente, já havia definido essa ideia, quando relata nas suas Leis o espírito do Estado de Licurgo (Op. cit., p. 110).

As crianças, futuros guerreiros de Esparta, eram "criadas", anatrophé, por seus pais, em suas casas, até os sete anos de idade; depois, essa tarefa era assumida pelo governo, sendo treinados para a obediência em situações penosas e difíceis ${ }^{3}$.

Desse modo, Licurgo não colocou a educação nas mãos nem de mercenários nem de servos comprados; os pais não poderiam educar seus filhos a seu bel prazer. Quando completavam sete anos, eram divididos em grupos a fim de serem educados juntos e brincassem entre si, aprender e estudar uns com os outros. Aquele que sobressaísse e fosse mais valente em combate, se tornaria o líder de todo o grupo, os outros deveriam obedecer as suas ordens. $\mathrm{O}$ legislador considerava a educação das crianças como a coisa mais bela que um legislador pudesse estabelecer (PLUTARCO. Licurgo XXV, XXXIII. In: Vidas Paralelas).

Dos sete aos quinze anos, eram instruídos nas letras e nos cálculos e, naturalmente, nos hinos do poeta Tirteu, que ressaltavam a bravura e a coragem destemida.

$\mathrm{Na}$ etapa final, entre dezesseis e vinte anos, quando denominados de eirén, um pouco antes de entrarem no serviço da pólis, eram treinados a manusear as armas, na luta com lanças e espadas, no arco e flecha. Com isso, a carga dos exercícios e as operações militares simuladas, nas montanhas ao redor da pólis, eram aumentadas.

Plutarco dá o seguinte testemunho:

Quanto às letras, aprendiam somente o necessário e, em suma, todo o aprendizado consistia em bem obedecer, suportar o trabalho e obter a vitória em combate. Por essa razão, à medida que avançavam em idade, aumentavamlhes também os exercícios corporais; raspavam-lhes os cabelos, faziam-nos andar descalços e os constrangiam a brincar juntos a maior parte do tempo inteiramente nus; depois, quando chegavam à idade de doze anos, não mais usavam saios daí por diante, pois todos os anos lhes davam somente uma túnica simples, o que era causa de andarem sempre sujos e

\footnotetext{
${ }^{3}$ Plutarco dá testemunho que estrangeiros se dirigiam até a Lacônia para contratarem amas para criarem seus filhos (PLUTARCO. Licurgo XXXII. In: Vidas Paralelas).
} 
ensebados, como aqueles que não se lavavam nem se untavam senão em certos dias do ano, quando os faziam gozar um pouco, dessa doçura. Deitavam e dormiam juntos sobre enxergas, que eles próprios fabricavam com pontas dos juncos e caniços que cresciam no rio Eurotas, os quais eles próprios deviam ir colher e quebrar, somente com as mãos, sem nenhuma ferramenta; mas, no inverno, ajuntavam a isso e misturavam no meio o que se chama Lycophanos, porque parece que essa matéria tem em si um pouco de calor. (PLUTARCO. Licurgo, XXIV. In: Vidas Paralelas)

A agogé, propriamente dita, se iniciava aos sete anos e finalizava até os vinte anos, compreendendo, portanto um período de treze anos. Havia a supervisão de um paidonómos, uma espécie de magistrado especial.

Marrou oferece a seguinte divisão da agogé, agrupados em três ciclos (MARROU, 1966, p. 42):

Oitavo ano ao décimo primeiro ano:

a) rhobídas (termo obscuro)

b) promikkizómenos (meninote)

c) mikki(khi)zómenos (menino)

Décimo segundo ano ao décimo quinto ano:

a) pratopámpais (rapaz já maduro de primeiro ano)

b) hatropámpais (rapaz já maduro de segundo ano)

c) melleíren (futuro irene)

d) melleíren (irene de segundo ano)

Décimo sexto ano ao vigésimo ano:

a) eirén de primeiro ano
b) eirén de segundo ano
c) eirén de terceiro ano
d) eirén de quarto ano
e) proteîras (irene-chefe)

O historiador francês pontua que os meninos espartanos eram divididos em unidades (ílai ou agélai), comandadas pelos jovens maiores, os proteîrai de vinte anos, que eram os mais velhos dentre os irenes (Op. cit., p. 43).

Plutarco lembra que os espartanos "não usam de muita linguagem", eram lacônicos, "pessoas de poucas palavras", como resultado, não se expressavam com propriedade, mas nada os impedia de serem bem compreendidos pelos ouvintes. $\mathrm{O}$ biógrafo sublinha que o próprio Licurgo era breve no falar. Interessante destacar que era proibido entrar em Esparta algum retórico para ensinar a arte da persuasão ao povo. Não obstante, os espartanos eram exímios compositores de belos cânticos, em que incitavam a coragem (PLUTARCO. Licurgo XIV, XL, XLIV. In: Vidas Paralelas).

Quando estavam reunidos em Conselho, os cidadãos espartanos não poderiam deliberar, indagar seus superiores; muito menos, apresentar alguma opinião, lhes era permitido, somente, aprovar ou reprovar os informes propostos pelos reis ou senadores (Op. cit., $\mathrm{X})$.

O futuro guerreiro tinha de ter, por hábitos, a modéstia, andar nas ruas com as mãos dentro do manto e caminhar em silêncio, sem dirigir o olhar a nenhum lugar, apenas olhando em direção a seus próprios pés. O historiador Xenofonte compara o jovem 
espartano, que anda em silêncio e de olhos baixos, a uma estátua de virgem (JENOFONTE. La Republica de los Lacedemonios).

Entre vinte e trinta anos, os espartanos eram obrigados a se casar, mas a vida familiar não era lhes permitida: só depois dos trinta, podiam deixar de dormir nos acampamentos militares.

A fim de dotar de coragem os seus infantes, em Esparta, havia a kryptía, um "esquadrão de extermínio", que estimulava os jovens selecionados a caçarem sozinhos ou em grupos os hilotas, ou seja, os escravos que, por um acaso, andassem desgarrados, ou que, de alguma forma, representassem, pelo seu vigor físico, uma ameaça à segurança da pólis. Os hilotas, quando localizados, eram vitimados pela espada ou pela lança, armas que o grupo de jovens sempre trazia consigo (PLUTARCO. Licurgo LVIII. In: Vidas Paralelas).

Os jovens espartanos estavam sempre forçando seus corpos ao limite, cultivando a excelência da força física. Aristóteles destaca que, de entre as cidades que mais se preocupavam com a educação infantil, a maioria procurava aperfeiçoá-la por meio de uma disposição atlética. O filósofo sublinha que os espartanos davam para os futuros guerreiros trabalhos árduos, como se essa atitude fosse vista como adequada para o culto da bravura (ARISTÓTELES. Política II 1338b, 10-15).

O estagirita ressalta que não é contra a ginástica, mas deve-se praticá-la com moderação até a adolescência, evitando exercícios forçosos, pois podem resultar em prejuízos para o corpo. Dá como exemplo que, de entre os vencedores dos jogos Olímpicos, tem, apenas, dois ou três espartanos vitoriosos. Acredita que isso se dá ao fato de terem sido sujeitos, desde criança, a treinos físicos extremos que acabaram por exaurir suas forças (Op. cit., II 1338b 35-40 / 1339a 1-5).

Aristóteles sublinha que toda a organização legislativa dos espartanos tinha como objetivo uma forma de virtude, o valor guerreiro, uma vez que é útil para dominar. Como resultado disso, o vigor e a força dos espartanos foram preservados, enquanto estiveram em guerra, mas houve um declínio a partir do momento que alcançaram a supremacia. $\mathrm{Na}$ verdade, não sabiam viver em paz, além do mais, não haviam se exercitado em outra disciplina, superior à arte da guerra (Op. cit., II 1271b, 1-10).

Jaeger sustenta que, na vida dos espartanos, por meio de uma educação diferenciada, percebe-se um ideal de educação análogo ao que Platão propõe na República. A propósito, Platão e outros teóricos da educação posteriores tiveram Esparta, por paradigma, em muitos aspectos (JAEGER, 2001, p. 112).

A necessidade de imposição dos espartanos sobre a grande maioria de hilotas (escravos que não possuíam direito algum), que, a qualquer momento, poderiam se rebelar, teve muita importância na formação da agogé espartana.

Ora, com as muitas conquistas espartanas, havia sempre a iminência de uma revolta por parte dos povos conquistados. É fato que os povos conquistados constituíam em maior número do que os conquistadores espartanos.

Acredita-se que, no final do século VI a.C., depois da conquista da Messênia, o estado espartano completou sua organização, transformando-se em um verdadeiro "acampamento militar" permanente.

Os resquícios arqueológicos atestam que até o século VI a.C., Esparta era dominada por uma aristocracia de grandes proprietários. Devido às duas grandes guerras pela conquista da Messênia, houve um aumento considerável daqueles que poderiam participar da função guerreira e que se beneficiaram pela distribuição de lotes, de clerói, 
da região conquistada. Por outro lado, os messênios foram reduzidos à condição de hilotas. A respeito da segunda guerra da $\mathrm{Messênia}^{4}$, Mossé escreve:

\begin{abstract}
Esparta parece ter se fechado em si mesma, com a decadência do artesanato e o desaparecimento do uso da moeda de prata. Diante da massa de populações dependentes (hilotas da Lacônia e da Messênia, periecos da Lacônia, motacos, neodamodos etc), a classe guerreira dos homoioí, dos semelhantes formada pelo conjunto dos cidadãos espartanos, passa a ser um grupo privilegiado que vive recluso em perpétuo estado de defesa. Essa é a origem da vida austera que tanto impressionava seus contemporâneos e permitia a Esparta desempenhar papel preponderante no mundo grego (MOSSÉ, 2004, p. 121). Com efeito, muitas disposições referentes à educação e ao casamento não deixam de evocar os programas educativos elaborados por Platão na República e nas Leis. Platão teria tomado o modelo espartano como inspiração, ou nos séculos seguintes esse modelo teria sido construído a partir das disposições imaginadas por Platão para suas cidades ideais? Essa é uma pergunta de resposta difícil. O que é inquestionável é o caráter peculiar da educação espartana, essa agogé que espantava os atenienses da época clássica, especialmente na medida em que também atingia as mulheres. (Op. cit., p. 189)
\end{abstract}

Ressalte-se que a guerra é um dos fenômenos a ser evitado, mas que, frequentemente, ocorre nas sociedades humanas. Em O Homem Grego, obra organizada por Vernant, o ensaio de Garlan denominado "O Homem e a Guerra" é relevante, pois, de acordo com Garlan, embora o homem grego "não pudesse ser definido como alguém que gosta da violência pela violência", isto é, como um homo militaris, muitos são os conflitos em que eles se envolveram, sobretudo na época arcaica e clássica. Para Garlan, é "como se a paz fosse, desde o primeiro momento, considerada precária ou mesmo concebida como uma espécie de trégua prolongada" (GARLAN apud VERNANT, 1994, pp. 49-50).

Em uma sociedade predominantemente guerreira como a espartana, a covardia de um guerreiro era vista com repugnância; assim, a desonra em Esparta acompanhava os covardes, sendo preferível a morte a uma vida infame e desonrosa. É um guerreiro que não merecia nenhuma timé, "honra", pois tem como aliados a atimíe, "desonra", e a kakótes, "covardia". Consequentemente, este homem é alguém sem aidós, ou seja, alguém que não é digno "de respeito", "de consideração". Há, pois, uma conexão clara entre aidós, "respeito" e timé, "honra", na sociedade espartana.

O binômio aidós, "respeito" e aiskhrýne, "vergonha", são vocábulos que estão presentes no estatuto cívico de Esparta, como pontua Nicole Loraux (LORAUX, 1989, p. 82).

O desenvolvimento da coragem era uma obsessão espartana, os guerreiros não poderiam ter medo de nada, deveriam ser resistentes aos ferimentos, odiando qualquer

\footnotetext{
${ }^{4}$ Houve duas guerras entre Messênia e Esparta. Na primeira, os espartanos, sob a liderança do rei Theopompo, foram vencedores. Os messênios eram comandados por Aristomenes. Segundo Heródoto (HERÓDOTO. História VIII, 131.2), o rei Theopompo pertencia à oitava geração antes de Leoticidas, que governou de 491 a 469 a.C. Depois de cinquenta anos de opressão, os messênios se revoltaram, com a ajuda de aliados de Argos, Arcádia e Pisa. Essa rebelião é conhecida como Segunda Guerra da Messênia. Campbell afirma que é difícil estabelecer a cronologia das duas guerras (CAMPBELL, 1967, p. 169). Costuma-se, contudo, fixar o período da primeira guerra em torno da segunda metade do século VIII a.C., mais precisamente entre 735 e 715 a.C. e a segunda guerra, que teria durado aproximadamente vinte e dois anos, na segunda metade do século VII a.C., por volta de 640-650 a.C.
} 
demonstração de covardia e, extremamente, dedicados à pólis. Toda a sociedade e educação espartana estavam voltadas para a guerra. Uma das frases atribuídas às mães espartanas era: "espero que o meu filho volte com o seu escudo ou deitado sobre ele".

Cada espartano era formado para ser um soldado perfeito e sua maior glória era morrer em batalha; retornar derrotado, jamais. Digno de nota, são os versos tirteanos: "Lutemos, com ardor, por esta terra e pelos filhos, morramos sem pouparmos nossas vidas" (10 W 13-14).

Em Esparta, a coragem fazia parte da formação do caráter de um homem. A propósito, Platão era também a favor da valentia de um guerreiro no campo de batalha (PLATÃO. República 468e).

Os dois primeiros versos do fragmento $10 \mathrm{~W}$ de Tirteu pontua dessa mentalidade de morrer pela pólis: "é belo morrer, caindo entre os combatentes das primeiras filas, um homem valente ao combater por sua terra" (10W 1-2).

A morte é bela quando é a de um herói que morre pela cidade. Esta ideia dá à morte o sentido de um "sacrifício" do próprio cidadão em prol de um bem mais alto: "a morte gloriosa". No mesmo fragmento, aliás, o poeta contrasta a morte gloriosa no campo de batalha, com a vida desventurada e errante do homem que não cumpriu na guerra seus direitos de cidadão, e se viu na necessidade de deixar a cidade (10W 9-12).

A linguagem de Tirteu é, em grande parte, herdeira de tradição épica. De um modo geral, as suas elegias demonstram um amplo conhecimento do vocabulário da Ilíada e da Odisseia, quando descreve a luta sangrenta e o heroísmo guerreiro. O ideal espartano é próximo da epopeia no que diz respeito à bravura, apesar de pertencerem a tempos literários diferentes.

Jaeger destaca que os versos tirteanos é o primeiro testemunho do ideal político e guerreiro, tendo, mais adiante, a sua realização na totalidade da educação espartana: "os seus poemas deixam ver, claramente, que a educação espartana, tal como as épocas seguintes a conheceram, não era uma coisa acabada, mas estava em processo de formação" (JAEGER, 2001, p. 115).

Qualquer fraqueza demonstrada era vista como pusilanimidade, algo, veementemente, repelido do seio daquela sociedade.

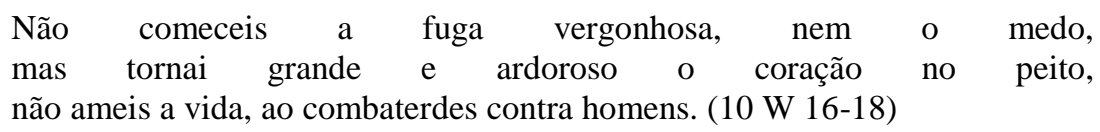

O modo de vida era regulamentado em função das necessidades do Estado e tinham consciência de não pertencerem a si próprios, mas à pólis:

\footnotetext{
Em suma, estimavam todos que não tinham nascido para servirem a si mesmos, antes para servir o país; e, portanto, se outra coisa não lhes era recomendada, continuavam sempre a ir ver o que faziam os meninos e a ensinar-lhes alguma coisa que resultasse em utilidade pública, ou ainda a aprender eles próprios com os que eram mais idosos do que eles. (PLUTARCO. Licurgo LI. In: Vidas Paralelas)
}

Licurgo teria imposto que os espartanos tivessem uma vida de austeridade, por exemplo, diz-se que eram obrigados a fazerem as refeições em comum em torno de um caldo negro (PLUTARCO. Licurgo, XXI. In: Vidas Paralelas).

Plutarco dá testemunho dessa coletividade: 
Em suma, acostumou os cidadãos a não quererem e não poder jamais viver sós, antes serem por assim dizer colados e incorporados uns com os outros, e a se acharem sempre juntos, como as abelhas, em torno dos superiores, saindo de si mesmos quase por um arrebatamento de amor para com o país e de desejo de honra para servir inteiramente ao bem da coisa pública. (Op. cit., LIV. In: Vidas Paralelas)

É bom lembrar que Licurgo ordenou que os espartanos fizessem as mesmas refeições juntos; era proibido se alimentarem à parte e em particular em grandes banquetes (Op. cit., XV. In: Vidas Paralelas).

Convém citar Aristóteles: "acreditamos que a amizade é o maior dos bens para as cidades, porquanto pode ser o melhor meio de evitar revoltas" (ARISTÓTELES. Política II $1262 \mathrm{~b}, 7-8)$.

O estagirita faz uma crítica a respeito das refeições comuns, intituladas de phidítia. Para o filósofo, essas refeições deveriam ser pagas pelo tesouro público, tal qual em Creta. Entretanto, em Esparta, os cidadãos tinham de fazer uma contribuição, até os pobres que tinham dificuldades de arrumar dinheiro para essas refeições. O objetivo de Licurgo era que essas refeições fossem democráticas: "a maneira espartana tradicional de fixar o limiar da cidadania, consiste em privar de participação o que não pode pagar a taxa das refeições comuns" (Op. cit., II 1271a, 26-30).

De acordo com o historiador Xenofonte, nas ações de guerra, os lacedemônios (espartanos) usavam traje vermelho, para que não se percebessem as manchas de sangue. Se morressem em combate, eram enterrados com essas túnicas (JENOFONTE. La Republica de los Lacedemonios $)^{5}$.

Na agogé espartana, a sophrosýne (temperança, moderação, autocontrole) tem um caráter social, sendo um comportamento imposto, regulamentado, marcado pelo comedimento que o jovem deve observar em todas as circunstâncias: comedimento em seu andar, em seu olhar, em suas expressões, comedimento diante das mulheres, em face dos mais velhos, comedimento aos prazeres, à bebida.

Desse modo, o futuro guerreiro era exercitado em dominar seus extintos. $\mathrm{Na}$ verdade, a agogé era, precisamente, destinada a experimentar esse poder de domínio de si. A sophrosýne submete assim cada indivíduo, em suas relações com o próximo em contraste com a hýbris, a "desmedida", a "transgressão".

O ideal da sophrosýne era: o nada em excesso; há uma tendência na qual a sophrosýne e a hýbris se encarnam, respectivamente, nos velhos e nos jovens (ideia que será mais clara nos trágicos).

A bela morte espartana deve ter ligação com a cidadania, ou melhor, um critério de cidadania, sendo uma manifestação cívica $(12 \mathrm{~W}, 18,34)$. Uma das diferenças mais acentuadas entre o mundo de Tirteu e dos poemas homéricos está nas relações do indivíduo com a comunidade, pois os guerreiros de Homero lutam pela glória individual, enquanto os heróis de Tirteu combatem pela comunidade, por suas famílias e dependentes. Assinale-se que há, na Ilíada XV, 494-9, um episódio em que Heitor está, claramente, lutando pela sobrevivência de Troia.

\footnotetext{
${ }^{5}$ Para Jaeger, a Constituição (República) dos Lacedemônios de Xenofonte é resultado do romantismo "meio filosófico meio político do século IV a.C., o qual via, no Estado espartano, uma espécie de revelação política primordial" (JAEGER, 2001, p. 109).
} 
A cidade espartana condena o ato de bravura de um só, combater e permanecer corajosamente no seu lugar na falange, não ceder à vontade de fugir, encorajar seu companheiro de linha é um bem comum para a cidade e para todo o povo.

Heródoto disserta a respeito do espartano Aristodamos que estava entre os trezentos lacedemônios que tinham defendido as Termópilas; ele foi o único sobrevivente, mas preocupado em livrar-se do opróbio que os espartanos infligiram a essa sobrevivência, o guerreiro saiu de seu posto, do seu lugar na falange e procurou e encontrou a morte em Plateia, ao realizar façanhas extraordinárias (HERÓDOTO. História IX, 71).

Além do exemplo de Aristodamos, o historiador dá testemunho de outro episódio nas Termópilas em que os combatentes, saindo de seus postos, lutavam de maneira furiosa em torno do corpo de Leônidas. Quando as espadas dos espartanos foram quebradas, eles se defenderam com as mãos e os dentes (Op. cit., VII, 225), em um estado de furor belicoso que se assemelhava aos heróis homéricos Diomedes e Aquiles. Os espartanos abandonaram a sophrosýne e estavam, claramente, em estado de lýssa, o que a cidade não tolerava.

Todavia, apesar de sua valentia, os espartanos não lhe concederam as honras fúnebres devidas aos melhores, isto é, recusaram-lhe a aristéia, porque violara a lei de permanecer em seu lugar na falange. Possuído pela lýssa, por um furor guerreiro, combateu, furiosamente, fora de seu posto.

A virtude guerreira não pertence à ordem do thymós, do impulso e sim da sophrosýne, a temperança, um domínio muito grande, para que o guerreiro pudesse refrear seus impulsos, e não perturbasse a ordem da formação em falange.

A ética militar espartana proíbe o estado de furor, de lýssa. Vernant destaca que a cidade rejeita atitudes tradicionais da aristocracia que tem por costume a exaltação do prestígio, do poder dos indivíduos e de colocá-los acima do comum, são considerados como um descomedimento, uma hýbris; de igual modo, o furor guerreiro e a busca no combate de uma glória particular (VERNANT, 2002, p. 69).

Até os sessenta anos, os espartanos estavam sujeitos a participar das guerras, pertenciam ao Estado ate à morte. As moças não eram tratadas de modo diverso: acima da família, vinha a pólis.

Xenofonte destaca que Licurgo ordenou que o sexo feminino exercitasse tanto quanto o masculino. A mulher espartana também tinha uma formação regulamentada, cuja música, a dança e o canto não possuíam tanta importância quanto a ginástica e o esporte (JENOFONTE. La Republica de los Lacedemonios 1, 4).

As espartanas estavam a serviço da cidade, quando solteiras, praticavam exercícios que a tornavam forte e saudável, a fim de que seus corpos se tornassem rígidos ao se exercitarem; havia exercícios de correr, de lutar, de jogar a barra e de lançar o dardo, com o objetivo de gerarem filhos, igualmente, robustos e para suportarem as dores do parto (PLUTARCO. Licurgo XXV. In: Vidas Paralelas).

Havia a ideia entre os homens de que pai e mãe fortes gerariam, igualmente, filhos mais vigorosos. Por isso, quando casada, a missão da mulher era dar ao Estado filhos fortes, grandes guerreiros e bons cidadãos. Percebe-se que há uma preocupação de eugenia dentro da sociedade espartana.

Os recém-nascidos eram observados e, se constatada qualquer imperfeição, essas crianças consideradas "defeituosas", que tivessem qualquer tipo de doença ou deformidade, eram, sumariamente, assassinadas, sendo atiradas de um precipício. Esses 
recém-nascidos não estariam prontos para defender a cidade-estado e, consequentemente, não seriam bons guerreiros na fase adulta ${ }^{6}$.

\begin{abstract}
Entrementes, depois que a criança nascia [...], mas, se lhes parecia feia, disforme ou franzina, mandavam atirá-la num precipício a que vulgarmente se dava o nome de Apothetes, isto é, depositórios, pois tinham a opinião de que não era expediente, nem para a criança, nem para a coisa pública, que ela vivesse, visto como desde o nascimento não se mostrava bem constituída para ser forte, sã e rija durante toda a vida. E, por esse motivo, as próprias mulheres que as governavam não as lavavam com água simples, como se faz por toda parte, mas com uma mistura de água e vinho, e por esse meio experimentavam se a compleição e a têmpera de seus corpos era boa ou má; porque dizem eles que as crianças sujeitas à epilepsia, ou então catarrosas e doentias, não podem resistir nem tolerar esse banho de vinho, mas definham e caem em langor; e, ao contrário, as que têm saúde se tornam mais rijas e mais fortes. (PLUTARCO. Licurgo XXXII. In: Vidas Paralelas)
\end{abstract}

Aristóteles sublinha que Licurgo, com o objetivo de fazer com que os espartanos fossem numerosos, encorajava-os a terem o maior número possível de filhos; há a lei de que o pai de três filhos está isento do serviço militar, e o de quatro, livre de impostos (ARISTÓTELES. Política II 1270b, 1-5).

A renomada helenista Claude Mossé infere que seria interessante acreditar que Esparta passou por uma série de etapas entre a adoção da falange hoplítica, século VII a.C. e o "fechamento da cidade em si mesma", início século IV a.C. Além do mais, a rhétra, que fora atribuída a um possível legislador, Licurgo, pode ter sido resultado de uma possível abertura da falange aos membros do dêmos, cuja participação, nas tomadas de decisão, era reconhecida. Em relação à partilha de terras, pode ter acontecido depois do término da segunda guerra da Messênia (último quarto do século VII a.C.), e a agogé e o militarismo da cidade podem ter ocorridos no princípio do século VI a.C., tendo por principal objetivo a defesa da cidade-estado espartana contra os povos da Lacônia e Messênia que foram escravizados.

A Esparta do século VII a.C. está empenhada em um movimento que leva as aristocracias das diversas cidades ao luxo. Depois, a ruptura se dá entre o final do século VII a.C. e o início do VI a.C.: concentra-se em si mesma, repudiando a ostentação da riqueza, proibindo o uso dos metais preciosos, depois a moeda de ouro e de prata (o dinheiro era feito de um ferro de má qualidade que não deveria ser fundido em grandes quantidades), permanece fora das correntes intelectuais, fecha-se a tudo o que é intercâmbio com o estrangeiro, comércio, atividade artesanal, voltam-se sua preocupação para a guerra em defesa da pólis (MOSSÉ, 2004, p. 189-190).

Qualquer riqueza não poderia ser exposta em público, os artesãos não confeccionavam luxos desnecessários, como tapetes e adornos, mas faziam muito bem apenas o básico, pois a riqueza seria a causa de muitos males. Xenofonte escreve que os espartanos não se adornavam com riquezas de vestuários, exceto com a boa forma física de seus corpos (JENOFONTE. La Republica de los Lacedemonios).

Pode-se conceituar a agogé como uma educação estatal com fins extremamente belicosos, que se estendia da infância até a adolescência. Nessa educação, os futuros

\footnotetext{
${ }^{6}$ Esse costume não ocorreu só em Esparta, a Lei das XII tábuas na Roma antiga autorizava os patriarcas a matar seus filhos frágeis ou deficientes.
} 
combatentes aprendiam as artes militares, as manobras em campos de batalha e a ser destemidos diante do inimigo.

Infere-se que o principal objetivo da agogé era formar poderosos guerreiros para a defesa da pólis. Para isso, uma rígida educação foi imposta aos jovens e uma peculiar maneira de viver aos adultos.

\section{REFERÊNCIAS}

ARISTÓTELES. Política. Edição Bilíngue. Tradução de Antônio Campelo Amaral e Carlos de Carvalho Gomes. Lisboa: Vega, 1998.

BAILLY, Anatole. Dictionnaire Grec-Français. Ed. Revista par L. Séchan e Chantraine. Paris: Hachette, 2000.

CAMPBELL, David A. Greek Lyric Poetry. New York: ST Martin’S Press, 1967.

DETIENNE, Marcel. La Phalange: problèmes et controverses. In: Problèmes de la Guerre en Grèce Ancienne. VERNANT, Jean-Pierre (org.). Paris: Éditons de l' École des Hautes Études en Sciences Sociales, Paris, 1999.

HERÓDOTO. História. Tradução de Mário da Gama Kury. Brasília: Editora Universidade de Brasília, 1988.

JAEGER, Werner. Paidéia: A formação do homem grego. São Paulo: Martins Fontes, 2001.

JENOFONTE. La Republica de los Lacedemonios. Tradução de Maria Rico Gomez. Madrid: Centro de Estúdios Costitucionales, 1989.

LORAUX, Nicole. Les Experiences de Tirésias: le féminin et l'homme grec. Paris: Gallimard, 1989, pp. 77-123.

MARROU, Henri-Irénée. História da Educação na Antiguidade. São Paulo: Herder, 1966.

MOSSÉ, Claude. Dicionário da Civilização Grega. Tradução de Carlos Ramalhete. Rio de Janeiro: Zahar Editor, 1998.

PEREIRA, Maria Helena da Rocha. Estudos de História da Cultura Clássica. Lisboa: Fundação Calouste Gulkbenkian, 1993.

PLATÃO. A República. Tradução de J. Guinsburg. São Paulo: Clássicos

Garnier/Difusão Europeia do Livro, 1965. 
A República. Tradução de Eduardo Menezes. São Paulo: Hemus Livraria Editora, 1970.

PLUTARCO. Licurgo. In: Vidas Paralelas. Tradução de Aristides da Silva Lobo. São Paulo: Ed. das Américas, s/d.

VERNANT, Jean-Pierre. O Homem Grego. Lisboa: Editorial Presença, 1994. Jean-Pierre. As Origens do Pensamento Grego. Rio de Janeiro: Difel, 2002.

WEST, Martin. Iambi et Elegi Graeci ante Alexandrum Cantati. New York: Oxford, 1992. 